Objectives: The aim is to assess the prevalence of fatigue and associated factors in a large sample of patients with axSpA patients from 13 European countries. Methods: Data from 2,846 unselected patients of the European Map of Axial Spondyloarthritis (EMAS) through an online survey (2017-2018) across 13 European countries were analyzed.

The presence of fatigue/tiredness was evaluated using the Visual Analogue Scale from the Bath Ankylosing Spondylitis Disease Activity Index (BASDAI): "How would you describe the overall level of fatigue/tiredness you have experienced? (0-10)". Risk of poor mental health was assessed using the 12-Item General Health Questionnaire (GHQ-12; 0-12).

Possible associated factors included: Socio-demographic and disease characteristics, disease activity and function and mental health disorders.

The Mann-Whitney test was used to compare the means of variables of two categories vs. the numerical variables, the $\chi^{2}$ test was used to compare the distribution between the categorical variables. Binary logistic regression and multiple linear regression were used to identify possible predictors.

Results: A total of 2,846 axSpA patients participated in the EMAS survey: mean age was 43.9 years, $61.3 \%$ female, $48.1 \%$ had a university degree, $67.9 \%$ were married and $71.3 \%$ were HLA-B27 positive. Fatigue/tiredness was associated with younger age $(6.4 \pm 2.3$ vs $5.5 \pm 2.4)$, being female $(6.6 \pm 2.2$ vs $5.7 \pm 2.4)$, lower educational level $(6.9 \pm 2.4$ vs $6.0 \pm 2.0)$ and separated or divorced persons $(6.8 \pm 2.2$ vs $6.2 \pm 2.3$; all $p<0.001)$. Those reporting work impact $(6.8 \pm 2.1$ vs $5.8 \pm 2.4)$, physically inactive $(6.9 \pm 2.2$ vs $6.1 \pm 2.3)$ or those with sleep disorders $(7.0 \pm 2.0$ vs $5.8 \pm 2.4)$, anxiety $(7.0 \pm 2.0$ vs $5.9 \pm 2.4)$ or depression $(7.2 \pm 1.9$ vs $5.9 \pm 2.4$; all $p<0.001)$ also presented greater fatigue, as did those with higher morning stiffness $(r=0.499)$ and functional limitation ( $r=0.257)$, and poorer mental health GHQ-12 ( $r=0.419)$. Finally, the variables independently associated with fatigue were female gender $(B=0.427)$, being physical inactive $(B=-0.395)$ and those with greater morning stiffness severity $(B=0.349$; see Table 1). In addition, those on temporary and permanent sick leave, along with the unemployed, presented greater fatigue (7.1, 6.8 and 7.1 respectively).

Table 1. Linear regression analysis to predict presence of fatigue/tiredness ( $N=2052)$

\begin{tabular}{|c|c|c|c|c|c|c|}
\hline & \multicolumn{3}{|c|}{ Simple } & \multicolumn{3}{|c|}{ Multivariate } \\
\hline & B & $95 \% \mathrm{Cl}$ & p-value & B & $95 \% \mathrm{Cl}$ & p-val \\
\hline Age & -0.018 & $-0.025,-0.011$ & $<0.001^{*}$ & -0.015 & $-0.022,-0.008$ & $<0.001$ \\
\hline Gender (female) & 0.838 & $0.659,1.017$ & $<0.001^{*}$ & 0.427 & $0.264,0.590$ & $<0.001$ \\
\hline Marital status (married) & 0.190 & $0.042,0.339$ & $0.012^{\star}$ & 0.162 & $0.021,0.302$ & $0.024^{*}$ \\
\hline Educational level (university) & -0.274 & $-0.402,-0.146$ & $<0.001^{*}$ & -0.128 & $-0.245,-0.012$ & $0.031^{*}$ \\
\hline BMI (Overweight/Obesity) & 0.151 & $-0.026,0.328$ & 0.094 & NA & NA & NA \\
\hline $\begin{array}{l}\text { Morning stiffness severity } \\
(0-10)^{*}\end{array}$ & 0.473 & $0.442,0.505$ & $<0.001^{*}$ & 0.349 & $0.314,0.385$ & $<0.00$ \\
\hline Functional limitation (0-54) & 0.038 & $0.032,0.044$ & $<0.001^{*}$ & 0.014 & 0.00 & $<0.001$ \\
\hline Reported Work impact (yes) & 0.936 & $0.753,1.119$ & $<0.001^{*}$ & 0.228 & $0.068,0.389$ & $0.005^{*}$ \\
\hline Physical activity (yes) & -0.726 & $-0.968,-0.485$ & $<0.001^{*}$ & -0.395 & $-0.611,-0.178$ & $<0.001^{*}$ \\
\hline Sleep disorder (yes) & 1.191 & $1.013,1.368$ & $<0.001^{*}$ & 0.276 & $0.095,0.458$ & $0.003^{*}$ \\
\hline Anxiety (yes) & 1.139 & $0.950,1.327$ & $<0.001^{*}$ & 0.002 & $-0.215,0.220$ & 0.982 \\
\hline Da & 1.274 & $1.079,1.469$ & $<0.001^{*}$ & 0.223 & $0.001,0.446$ & $0.049^{*}$ \\
\hline GHQ-12 $(0-12)$ ** & 0.234 & $0.215,0.254$ & $<0.001$ & 0.110 & $0.088,0.132$ & $<0.001 \times$ \\
\hline
\end{tabular}

${ }^{*}$ As measured by the respective item of the BASDAl scale ${ }^{\star *} 12$-item General Health Questionnaire. A value of 3 or above indicates a risk of poor mental health

Conclusion: Fatigue/tiredness was highly prevalent among axSpA European patients with female gender, engage in physical activity and those with greater morning stiffness severity most strongly associated, and the unemployed presenting greatest fatigue.

Acknowledgements: This study was supported by Novartis Pharma AG. The authors would like to thank all patients who participated in the study.

Disclosure of Interests: Marco Garrido-Cumbrera: None declared, Victoria Navarro-Compán Grant/research support from: Abbvie, BMS, Lilly, MSD, Novartis, Pfizer, Roche, and UCB, Laura Christen Employee of: Novartis Pharma AG, Christine Bundy Speakers bureau: Abbvie, Celgene, Janssen, Lilly, Novartis, and Pfizer., Raj Mahapatra: None declared, Souzi Makri: None declared, Carlos Jesús Delgado-Domínguez: None declared, José Correa-Fernández: None declared, Sergio Sanz-Gómez: None declared, Denis Poddubnyy Speakers bureau: Abbvie, BMS, Celgene, Janssen, Lilly, MSD, Novartis, Pfizer, Roche, and UCB., Grant/research support from: Abbvie, MSD, Novartis, and Pfizer. DOI: 10.1136/annrheumdis-2021-eular.968

\section{POS0961 PREVALENCE AND ASSOCIATED FACTORS OF SLEEP DISORDERS IN PATIENTS WITH AXIAL SPONDYLOARTHRITIS. RESULTS FROM THE EUROPEAN MAP OF AXIAL SPONDYLOARTHRITIS (EMAS)}

M. Garrido-Cumbrera ${ }^{1}$, V. Navarro-Compán ${ }^{2}$, L. Christen ${ }^{3}$, C. Bundy ${ }^{4}$, R. Mahapatra ${ }^{5}$, S. Makri' ${ }^{6}$, C. J. Delgado-Domínguez ${ }^{1}$, J. Correa-Fernández ${ }^{1}$,

D. Poddubnyy ${ }^{7}$ on behalf of IMAS working group. ${ }^{1}$ Universidad de Sevilla,
Health \& Territory Research (HTR), Seville, Spain; ${ }^{2}$ Hospital Universitario La Paz, IdiPaz, Madrid, Spain; ${ }^{3}$ Novartis Pharma AG, Patient Engagement, Basel, Switzerland; ${ }^{4}$ Cardiff University, School of Healthcare Sciences, Cardiff, United Kingdom; ${ }^{5}$ Axial Spondyloarthritis International Federation (ASIF), Patient Advocacy, London, United Kingdom; ${ }^{6}$ Cyprus League Against Rheumatism (CYPLAR), Patient Advocacy, Nicosia, Cyprus; ${ }^{7}$ Charité - Universitätsmedizin Berlin, Rheumatology Department, Berlin, Germany

Background: Sleep is an essential health aspect that is often impacted in patients with axial spondyloarthritis (axSpA).

Objectives: This analysis aims to assess the prevalence and associated factors of sleep disorders in a large sample of European axSpA patients.

Methods: Data were analyzed from 2,846 unselected patients with self-reported clinician-given diagnosis of axSpA of the European Map of Axial Spondyloarthritis (EMAS) through an online survey (2017-2018) across 13 European countries. Socio-demographic data; BASDAI [0-10] scores; engagement in physical activity; axSpA influence on work choice (assessed with yes/no question "Was your current or past work choice in any way determined by axSpA?"); risk of psychological distress (12-item General Health Questionnaire [GHQ-12; 0-12]); functional limitation [0-54] and self-reported anxiety and depression were evaluated. Presence of sleep disorders was assessed by the question: "Please indicate whether you have been diagnosed with any of the following: sleep disorders". A Mann-Whitney test was used to compare the means of numerical variables between dichotomous variables, the Chi-Square test was used to compare the distribution between the categorical variables. Simple and multivariable logistic regression models were used to identify associations between sleep disorders and disease characteristics, mental health and work-related variables.

Results: Age of respondents was 43.9 years; $61.3 \%$ were female; $48.1 \%$ had a university degree; $67.9 \%$ were married and $71.3 \%$ were HLA-B27 positive The prevalence of sleep disorders was $39.0 \%$. In the bivariate analysis, presence of sleep disorders was associated with female gender $(68.3 \%$ vs. $31.7 \%$; $\mathrm{p}<0.001)$; overweight/obese $(56.5 \%$ vs. $49.8 \%$; $\mathrm{p}<0.001)$; increased BASDAI scores ( $6.1 \pm 1.8$ vs. $5.0 \pm 2.1 ; p<0.001)$; fatigue $(7.0 \pm 2.0$ vs. $5.8 \pm 2.4 ; p<0.001)$ morning stiffness $(5.8 \pm 2.4$ vs. $4.8 \pm 2.4 ; p<0.001)$, work impact $(56.5 \%$ vs. $38.2 \%$ p< 0.001 ); anxiety (56.8\% vs. $12.5 \%$; $p<0.001)$; depression $(51.8 \%$ vs. $10.1 \%$; $\mathrm{p}<0.001)$ and higher GHQ-12 scores $(6.4 \pm 4.0$ vs. $3.9 \pm 3.9 ; \mathrm{p}<0.001)$. However factors that remained independently associated with sleep disorders in the multivariable analysis were anxiety $(\mathrm{OR}=3.8 \mathrm{p}<0.001)$ and depression $(\mathrm{OR}=3.1$ $\mathrm{p}<0.001)$ and female gender $(\mathrm{OR}=1.4 ; \mathrm{p}=0.002)$ [Table 1].

Table 1. Regression analysis to predict presence of sleep disorders $(\mathrm{N}=2191)$

\begin{tabular}{lcccccc}
\hline & \multicolumn{3}{c}{ Simple logistic regression } & \multicolumn{3}{c}{$\begin{array}{c}\text { Multivariable logistic } \\
\text { regression }\end{array}$} \\
\cline { 2 - 7 } & OR & $\mathbf{9 5 \%} \mathbf{~ C l}$ & p-value & OR & $\mathbf{9 5 \%}$ Cl & p-value \\
\hline Gender (female) & 1.59 & $1.36-1.87$ & $<0.001$ & 1.40 & $1.13-1.73$ & $\mathbf{0 . 0 0 2}$ \\
Marital status (married) & 1.13 & $0.99-1.28$ & 0.074 & $\mathrm{NA}$ & $\mathrm{NA}$ & $\mathrm{NA}$ \\
Overweight/Obesity & 1.31 & $1.12-1.53$ & $\mathbf{0 . 0 0 1}$ & 1.39 & $1.14-1.71$ & $\mathbf{0 . 0 0 1}$ \\
BASDAl (0-10) & 1.33 & $1.27-1.39$ & $<0.001$ & 1.07 & $0.95-1.21$ & 0.246 \\
Fatigue/Tiredness (0-10) & 1.28 & $1.23-1.33$ & $<0.001$ & 1.04 & $0.97-1.12$ & 0.271 \\
Morning Stiffness intensity (0-10) & 1.19 & $1.15-1.23$ & $<0.001$ & 1.05 & $0.98-1.13$ & 0.188 \\
Reported Work impact (yes) & 2.10 & $1.78-2.48$ & $<0.001$ & 1.29 & $1.05-1.58$ & $\mathbf{0 . 0 1 5}$ \\
Anxiety (yes) & 9.18 & $7.58-11.11$ & $<0.001$ & 3.84 & $2.99-4.94$ & $<0.001$ \\
Depression (yes) & 9.53 & $7.78-11.66$ & $<0.001$ & 3.09 & $2.37-4.02$ & $<0.001$ \\
GHQ-12 (0-12) & 1.16 & $1.14-1.19$ & $<0.001$ & 1.03 & $1.00-1.06$ & $\mathbf{0 . 0 2 9}$
\end{tabular}

${ }^{*}$ As measured by the respective item of the BASDAI scale.* 12 -item General Health Questionnaire. A value of 3 or above indicates a risk of poor mental health.

Conclusion: Sleep disorders were highly prevalent among axSpA European patients and strongly associated with female gender and reporting worse menta health, and spinal stiffness. Patients on permanent and temporary sick leave were more likely to report sleep disorders. The strong association between sleep disorders with both anxiety and depression should encourage rheumatologists to screen their patients with sleep disturbance in case they require additional specialist support.

Acknowledgements: This study was supported by Novartis Pharma AG. The authors would like to thank all patients who participated in the study.

Disclosure of Interests: Marco Garrido-Cumbrera: None declared, Victoria Navarro-Compán Grant/research support from: Abbvie, BMS, Lilly, MSD, Novartis, Pfizer, Roche, and UCB., Laura Christen Employee of: Novartis Pharma AG, Christine Bundy Speakers bureau: Abbvie, Celgene, Janssen, Lilly, Novartis, and Pfizer, Raj Mahapatra: None declared, Souzi Makri: None declared, Carlos Jesús Delgado-Domínguez: None declared, José Correa-Fernández: None declared, Denis Poddubnyy Speakers bureau: Abbvie, BMS, Celgene, Janssen, Lilly, MSD, Novartis, Pfizer, Roche, and UCB, Grant/research support from: Abbvie, MSD, Novartis, and Pfizer.

DOI: 10.1136/annrheumdis-2021-eular.981 